\title{
PRODUCTIVITY AND COMPETITIVENESS - AN ANALYSIS
}

\author{
T.B.Pankhania ${ }^{1}$, A.H.Jariya ${ }^{2}$, V.K.Modi ${ }^{3}$ \\ ${ }^{1}$ Associate Professor in Mechanical Engineering and Head, Workshop, B.V.M.Engineering College, Sardar Patel \\ University, Vallabh Vidyanagar, Anand, Gujarat, India.tbp@sify.com \\ ${ }^{2}$ Assistant Professor in Production Engineering B.V.M. Engineering College, Gujarat Technological University, \\ Ahmadabad, India,jariya_akil@yahoo.com \\ ${ }^{3}$ Lecturer, Mechanical Engineering Department, B.\&B. Institute of Technology, Vallabh Vidyanagar, Gujarat \\ Technological University, Ahmadabad, Gujarat, India, modi_vinit@yahoo.com
}

\begin{abstract}
The paper explores the impacts of globalization on industrial performance and productivity. It also records the effects of ISO certification on industries' image and performance. The hypotheses were tested to know how far these statements hold good. For that Chi-Square tests were carried out to know the impacts of globalization and competitions in the present industrial scenario. Regression analysis also highlights the relation between income and Category of industries in the estate considered for the study. The structured questionnaire was used as a tool to collect primary data to use for the statistical analysis. The reliability statistic, Cronbatch's alpha suggests that questionnaire is with consistency and can be used for the analysis. It is concluded that globalization and competitiveness are strongly correlated with improved industrial performance and productivity scenario.
\end{abstract}

Keywords: Competitiveness, explore, globalization, impacts, performance, questionnaire, reliability, scenario

\section{INTRODUCTION}

Two third of today's business operate globally through global markets, global operations, global financing, and global supply chains. A global marketplace for products and services means more customers and more intense competition. In the broadest terms, we speak of competitiveness in reference to other countries rather than to other companies. That's because how effectively a nation competes in the global marketplace, affects the economic success of the nation and the quality of life for its citizens. The U.S. department of commerce defines competitiveness as "the degree to which a nation can produce goods and services that meet the test of international markets while simultaneously maintaining or expanding the real incomes of its citizens". The most common measure of competitiveness is productivity. Increases in productivity allow wages to grow without producing inflation thus raising the standard of living. Productivity growth also represents how quickly an economy can expand its capacity to supply goods and services [16].

Safety and Productivity has positive relationship with each other. In order to have higher productivity it is essential to provide better and safe working conditions.

Naturally, any kind of loss is directly affecting the productivity of the organization. So, better and safe working environment can reduce the chances of accidents. This will create good reputation in the market [18].
Good housekeeping is more than cleanliness; it is good in order, when there are no unnecessary things about, and when all necessary things are in their proper places. The better the worker, the higher the production, and the lower the accident rare, better the performance leading to higher productivity [17].

\section{RELEVANCE OF THE STUDY}

In the present age of cut-throat competition, it becomes highly necessary for an organisation to be dynamic in the globalisation era. This is possible only when the employees, employers and organizations are capable enough to cope up with the changing world scenario. The present changing scenario in the globalization, an organization cannot be run merely on investment and returns, but more on the quality of their products, services, human resource, productivity, timeliness, cost-reduction and its commitment to organization's goals. Therefore, the industrial productivity became the centre of attention as far as the research is concerned. In the present industrial scenario the organization has to maintain good standard to stand in the highly competitive world of globalization [6].

Talent is often cited as a key differentiator for competitive success. As more and more organisations realised that managing talent effectively is the key to business success; it is a topic of interest to both industry and academia. Human capital organisations not only have good talent, but, talent attraction, retention, and performance are essential for organisational capability [7]. 


\section{OBJECTIVES OF THE STUDY}

The primary objective of this research was to take the stock of existing situations and to assess the industrial productivity and the major impacts of globalization and competitiveness on industrial performance.

\section{RESEARCH DESIGN}

Research design is a road map of the collection, measurement and analysis of data. The present study was conducted in Vitthal Udyognagar, an industrial estate in Anand district of Gujarat, India. The units were selected from the members' directory published by Vitthal Udyognagar Industries Association (VUIA). The basic methodology that followed was the questionnaire method. Structured questionnaires were distributed among the randomly selected organizations. The five point Likert scale: strongly agree (05), agree (04), neutral (03), disagree (02) and strongly disagree (01) was used. The questionnaires were checked for incomplete, inconsistent, and ambiguous responses. The questionnaires were discarded with large proportion of unsatisfactory responses and this has resulted in final sample size as shown in Table 1.

Table -1: Sample size and percentage

\begin{tabular}{|c|c|c|}
\hline $\begin{array}{c}\text { Questionnaire } \\
\text { distributed }\end{array}$ & $\begin{array}{c}\text { Questionnaire } \\
\text { Usable }\end{array}$ & Percent \\
\hline 250 & 156 & 62.40 \\
\hline
\end{tabular}

These responses were considered from usable questionnaires, $62.40 \%$ is acceptable for the statistical analysis.

Category of the Company: Majority units are in small scale. In this survey $70.51 \%$ (110), small scale, $19.23 \%$ (30), medium scale and $10.26 \%(16)$, large scale units have provided relevant data for this research study, see Table 2.

Table - 2: Category of the company

\begin{tabular}{|l|c|c|}
\hline \multicolumn{1}{|c|}{ Category } & Frequency & Percentage \\
\hline Small Scale & 110 & 70.51 \\
\hline Medium Scale & 30 & 19.23 \\
\hline Large Scale & 16 & 10.26 \\
\hline Total & 156 & 100.00 \\
\hline
\end{tabular}

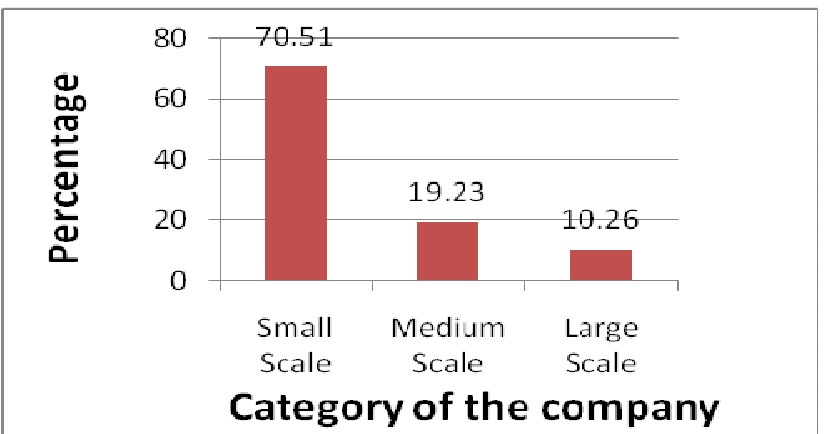

Chart -1: Category of the company

\section{STATISTICAL ANALYSIS}

\subsection{An Index of Reliability}

An effective tool for measuring reliability is Cronbach's alpha, which is a numerical coefficient of reliability. Alpha coefficient ranges in value from 0 to 1 and may be used to describe the reliability of factors extracted. The higher the score, the more reliable is the generated scale, alpha value 0.7 to be considered as an acceptable reliability. Table 3 shows the reliability measures [4].

Table - 3: Reliability Statistic

\begin{tabular}{|c|c|l|}
\hline Sr. No. & Cronbach's Alpha & Internal Reliability \\
\hline 1 & $\geq 0.90$ & Excellent \\
\hline $\mathbf{2}$ & $\geq \mathbf{0 . 8 0}$ & Good \\
\hline 3 & $\geq 0.70$ & Acceptable \\
\hline
\end{tabular}

Here, the questionnaire is reliable with Cronbatch's alpha $(\alpha)$ $=0.838$ and it can be used for statistical analysis.

\subsection{Globalization and Competitiveness Impacts}

For this purpose t-test was carried out with assumed mean $(\mu)$ $=3.0$, on the responses of the statements on five points scale, the middle part was considered as 'Neutral' for all statements and was given an equivalent number of 3.0. The result of these test are given in the following Table 4 and Table 5.

Table - 4: One-Sample Statistics ( $\mathrm{t}$ - test)

\begin{tabular}{|c|c|c|c|c|}
\hline Statement & $\mathrm{N}$ & Mean & SD & SE Mean \\
\hline 1 & 156 & 4.48 & 0.876 & 0.070 \\
\hline 2 & 156 & 4.20 & 0.926 & 0.074 \\
\hline 3 & 156 & 4.10 & 0.924 & 0.074 \\
\hline 4 & 156 & 4.38 & 1.144 & 0.092 \\
\hline 5 & 156 & 4.14 & 1.277 & 0.102 \\
\hline 6 & 156 & 3.80 & 1.302 & 0.104 \\
\hline 7 & 156 & 3.81 & 1.281 & 0.103 \\
\hline
\end{tabular}


Table - 5: One-Sample test

Test Value $=3$

(95\% Confidence Interval of the Difference)

\begin{tabular}{|c|c|c|c|c|c|c|}
\hline State & 't' & DF & $\begin{array}{c}\text { Sig. } \\
(* *)\end{array}$ & $\begin{array}{c}\text { Mean } \\
\text { Difference }\end{array}$ & Lower & Upper \\
\hline 1 & 21.113 & 155 & 0.000 & 1.481 & 1.34 & 1.62 \\
\hline 2 & 16.173 & 155 & 0.000 & 1.199 & 1.05 & 1.35 \\
\hline 3 & 14.902 & 155 & 0.000 & 1.103 & 0.96 & 1.25 \\
\hline 4 & 15.053 & 155 & 0.000 & 1.378 & 1.20 & 1.56 \\
\hline 5 & 11.157 & 155 & 0.000 & 1.141 & 0.94 & 1.34 \\
\hline 6 & 7.685 & 155 & 0.000 & 0.801 & 0.60 & 1.01 \\
\hline 7 & 7.877 & 155 & 0.000 & 0.808 & 0.61 & 1.01 \\
\hline
\end{tabular}

\subsubsection{Statements and Analysis}

\section{Globalization has changed Industrial}

Scenario and it's a demand of the day, increases

\section{productivity}

The hypothesis is rejected because the mean of all the responses 4.48 (Table $4 \& 5$ ) which is higher than the assumed value of $\mu=3.0$ and that has led to the rejection of null hypothesis. Thus, a mean of 4.48 is very high value and it shows that all the respondents in general agree to the statements that 'Globalization has changed industrial scenario and it's a demand of the day, increases productivity'. As the low value of standard deviation 0.876 and mean equal to 4.48 shows that average response of all the respondents falls between strongly agree and agree to the said statement and there is very less dispersion between the thinking of all the respondents. It may, therefore, be inferred that in general all the respondents associate 'globalization has changed industrial scenario and it's a demand of the day, increases productivity'.

\section{Job opportunities, productivity and living}

\section{standards have increased due to globalization.}

The hypothesis is rejected because the mean of the responses of all the responses is 4.20 (Table $4 \& 5$ ) which is higher than the assumed value of $\mu=3.0$ and that has led to the rejection of null hypothesis. Thus, a mean of 4.20 is very high value and it shows that all the respondents in general agree to the statement. As the low value of standard deviation 0.926 and mean equal to 4.20 shows that average response of all the respondents falls between strongly agree and agree to the said statement and there is very less dispersion between the thinking of all the respondents. It may, therefore, be inferred that in general all the respondents associate ' job opportunities, productivity and living standards have increased due to globalization'.

\section{Liberalization has improved performance and competitiveness}

The hypothesis is rejected because the mean of the all responses is 4.10 (Table 4\&5) which is higher than the assumed value of $\mu=3.0$ and that has led to the rejection of null hypothesis. Thus, a mean of 4.10 is very high value and it shows that all the respondents in general agree to the statement. As the low value of standard deviation 0.924 and mean equal to 4.10 shows that average response of all the respondents falls between strongly agree and agree to the said statement and there is very less dispersion between the thinking of all the respondents. It may, therefore, be inferred that in general all the respondents, associate 'liberalization has improved performance and competitiveness'.

\section{Privatizations are very essential to improve industrial performance in the highly competitive world}

The hypothesis is rejected because the mean of the responses of all the organization is 4.38 (Table $4 \& 5$ ) which is higher than the assumed value of $\mu=3.0$ and that has led to the rejection of null hypothesis. Thus, a mean of 4.38 is very high value and it shows that all the respondents in general agree to the statement. As the high value of standard deviation 1.144 is quite large and means equal to 4.38 shows that there is variation in the thinking of all the respondents. Average response of all the respondents falls between strongly agrees and agrees to the said statement and there is diverse view on this statement.

\section{ISO certification helps improve the image of}

\section{the company}

The hypothesis is rejected because the mean of the responses of all the organization is 4.14 (Table $4 \& 5$ ), which are higher than the assumed value of $\mu=3.0$ and that have led to the rejection of null hypothesis. Thus, a mean of 4.14 is very high value and it shows that all the respondents in general agree to the statement. As the high value of standard deviation 1.277 is quite large and means equal to 4.14 shows that there is variation in the thinking of all the respondents. Average response of all the respondents falls between strongly agrees and agrees to the said statement and there is diverse view on this statement.

\section{ISO certification helps increase exports; profit, turnover, expectations of the company}

The hypothesis is rejected because the mean of the responses of all the organization is 3.80 (Table $4 \& 5$ ) which is higher than the assumed value of $\mu=3.0$ and that has led to the rejection of null hypothesis. Thus, a mean of 3.80 is high value and it 
shows that all the respondents in general agree to the statement. As the high value of standard deviation 1.308 is quite large and means equal to 3.80 shows that there is variation in the thinking of all the respondents. Average response of all the respondents falls between agrees and neutral to the said statement and there is diverse view on this statement.

\section{ISO certification helps increase productivity}

The hypothesis is rejected because the mean of the responses of all the organization is 3.81 (Table $2 \& 3$ ) which is higher than the assumed value of $\mu=3.0$ and that has led to the rejection of null hypothesis. Thus, a mean of 3.81 is high value and it shows that all the respondents in general agree to the statement. As the high value of standard deviation 1.281 is quite large and means equal to 3.81 shows that there is variation in the thinking of all the respondents. Average response of all the respondents falls between agrees and neutral to the said statement and there is diverse view on this statement.

Thus, globalization and competitiveness has very high impacts on the industrial performance to compete the global business.

\subsection{Analysis of Variance (ANOVA)}

One of the most powerful tools of statistical analysis is what is known as analysis of variance. Analysis of variance is used for examining the differences in the mean values of the dependent variable associated with the effect of the controlled independent variables. Essentially, analysis of variance is used as a test of means of two or more population [6].

\subsubsection{Relation between Respondents' Annual Income}

\section{and Categories of the Company: (Small Scale,}

\section{Medium Scale and Large Scale Industries).}

Table -6: Descriptive table

Variable: Annual income $\leftrightarrow$ Scale of the company

\begin{tabular}{|c|c|c|c|c|c|c|}
\hline $\begin{array}{c}\text { Income } \\
\text { Group }\end{array}$ & $\mathrm{N}$ & Mean & $\mathrm{SD}$ & $\mathrm{SE}$ & \multicolumn{2}{|c|}{$\begin{array}{c}\text { 95\% Confidence } \\
\text { Interval for Mean }\end{array}$} \\
\cline { 5 - 7 } & & & & & LB & $\mathrm{UB}$ \\
\hline 1 & 22 & 1.14 & 0.351 & 0.075 & 0.98 & 1.29 \\
\hline 2 & 55 & 1.33 & 0.579 & 0.078 & 1.17 & 1.48 \\
\hline
\end{tabular}

\begin{tabular}{|c|c|c|c|c|c|c|}
\hline 3 & 56 & 1.52 & 0.763 & 0.102 & 1.31 & 1.72 \\
\hline 4 & 23 & 1.52 & 0.790 & 0.165 & 1.18 & 1.86 \\
\hline Total & 156 & 1.40 & 0.669 & 0.054 & 1.29 & 1.50 \\
\hline
\end{tabular}

Table 6: To study the impact of scale of company on annual income of the respondents, analysis of variance was performed. The hypotheses are as under:

$\mathrm{H}_{0 \text { : }}$ there is no impact of scale of industry on annual income of the respondents.

$\mathrm{H}_{1}$ : there is impact of scale of industry on annual income of the respondents.

Table -7: ANOVA

Variable: Annual income $\leftrightarrow$ Scale of the company

\begin{tabular}{|c|c|c|c|c|c|}
\hline & $\begin{array}{c}\text { Sum of } \\
\text { Squares }\end{array}$ & DF & $\begin{array}{c}\text { Mean } \\
\text { Square }\end{array}$ & F & Sig. \\
\hline $\begin{array}{c}\text { Between } \\
\text { Groups }\end{array}$ & 2.938 & 3 & 0.979 & 2.241 & 0.086 \\
\hline $\begin{array}{c}\text { Within } \\
\text { Groups }\end{array}$ & 66.421 & 152 & 0.437 & & \\
\hline Total & 69.359 & 155 & & & \\
\hline
\end{tabular}

Table-7: The test is performed at 5\% level of significance (95\% level of confidence). The significance value is 0.086 $>0.05$. The null hypothesis is not rejected and alternative hypothesis is accepted. Hence it is concluded that there is an impact of scale of industry on annual income of the respondents.

\subsection{The Chi-Square $(\chi 2)$ Test}

It assists us in determining whether a systematic association exists between the two variables. It helps us to understand how one variable relates to another variable, statistics are available for examining the significance and strength of the association[15] 
Table - 8: Globalization Impacts

\begin{tabular}{|c|c|c|c|c|c|c|c|c|}
\hline Sr. No. & Variables & (05) & (04) & (03) & $(02)$ & (01) & Total & \multirow{5}{*}{$\begin{array}{l}\boldsymbol{\chi}^{\mathbf{2}} \text { at } \mathbf{D F}=\mathbf{1 2} \\
\mathrm{CV}=77.54, \mathrm{P}<0.0001 \\
\mathrm{TV}=21.026, \mathrm{LSF}=0.05 \\
\mathrm{~V}=0.2035\end{array}$} \\
\hline 1 & Industrial Scenario & 97 & 48 & 7 & 0 & 4 & 156 & \\
\hline 2 & Living Standard & 63 & 74 & 15 & 1 & 3 & 156 & \\
\hline 3 & Liberalization & 54 & 76 & 23 & 0 & 3 & 156 & \\
\hline 4 & Privatization & 105 & 29 & 11 & 7 & 4 & 156 & \\
\hline
\end{tabular}

$\chi^{2}=$ Chi-square, $\mathrm{DF}=$ Degree of freedom, $\mathrm{CV}=$ Calculated value of Chi-square test, $\mathrm{TV}=$ Table value, $\mathrm{LSF}=$ Level of significance

Table 8: The "globalization" has positive relation. The employees are in agreement on the global effects in the organization where they are serving. Since, $\chi_{\mathrm{cv}}{ }^{2}=77.54^{>} \chi_{\mathrm{tv}}{ }^{2}=$
21.026 , it has mentioned that the "globalization" is highly effective in making organization more competitive and more productive.

Table -9: ISO Certification

\begin{tabular}{|c|c|c|c|c|c|c|c|c|}
\hline Sr. No. & Variables & $(05)$ & $(04)$ & $(03)$ & $(02)$ & $(01)$ & Total & $\chi^{2}$ at $\mathrm{DF}=8$ \\
\hline 5 & Image of the company & 86 & 40 & 15 & 11 & 4 & 156 & $\mathrm{CV}=16.97, \mathrm{P}=0.0304$ \\
\hline 6 & Expectation of the company & 58 & 50 & 27 & 13 & 8 & 156 & $\mathrm{TV}=15.507, \mathrm{LSF}=0.05$ \\
\hline 7 & Increase Productivity & 55 & 56 & 25 & 12 & 8 & 156 & $\mathrm{~V}=0.1346$ \\
\hline
\end{tabular}

$\chi^{2}=$ Chi-square, $\mathrm{DF}=$ Degree of freedom, $\mathrm{CV}=$ Calculated value of Chi-square test, $\mathrm{TV}=$ Table value, LSF $=$ Level of significance

Table 9: The "ISO certification" has low positive relation. Majority of the respondents were in agreement and only few respondents were not in favor where, they are serving. Since, $\chi_{\mathrm{cv}}{ }^{2}=16.97>\chi_{\mathrm{tv}}{ }^{2}=15.507$, it has mentioned that the "ISO certification" is required to improve the standard and the image of the company.

\section{LIMITATIONS OF THE STUDY}

The limitations of the study are non-availability of some secondary data, responses with reservation caused limited cooperation from some of the respondents, the postponements of the responses were time consuming and tiresome due to busy schedule or unwillingness to disclose certain information by the respondents, the time factors, poor awareness of some respondents were other limitations, lower education, language problem and lack of freedom to disclose the facts were major constraints to the most of the workers.

\section{CONCLUSION}

The paper clearly investigates on the basis of the stakeholders" point of views that globalization has changed the industrial scenario. This analysis clearly outlays that globalization and competitiveness has very high impacts on industrial performance to compete global markets. At the same time ISO Certification does not attract the stake holders. Those who failed to adopt the changes they will face failures miserably. Statistical analyses reveal that the hypotheses tested also inferred the same outcomes. There is impact of category of the industry on the annual income of the respondents. The Chi Square test also confirmed that there is global effects on industrial performance and There is imperative influence of ISO certification on industrial performance and hence, industrial productivity.

\section{ACKNOWLEDGEMENTS}

First of all, B.V.M.Engineering College for permission for research work, Sardar Patel University, Vallabh Vidyanagar, District Industries Centre, Anand for permitting to use all the records and related literatures of industrial scenario of Anand district. Resident District Collector, Anand and staff for providing related literatures of industrial scenario and records of Gujarat state. Executives of Amul Dairy, Anand for their help to furnish details and permit to visit of AMUL plants for the study of their performance enhancement programme. Secretariat of V. U. Industries Association, for their all time help for information and permission to use all available data, references. Corporate executives, who gave permission to study their organizations and helped in getting permissions from various industries of the estate. The researchers also acknowledges the valuable help and suggestions from individuals, industrialists, executives, managers, engineers, workmen during various stages of this research work and to all those organizations who had responded positively to the research questionnaires. 


\section{REFERENCES}

[1] Goal, Bharat and Dewan, Bhushan (2011). Factors affecting consumer preferences of shopping at organized retail stores in Punjab' Journal of Engineering, Science and Management Education, NITTTR, Bhopal. 4, 44-49.

[2] Heizer,Jay, Render Barry, (1999), Operations Management, Prentice-Hall, Int. New Jersey.

[3] Jani, H. J., (2004). Ph.D. Thesis, Quality Management in Indian Companies through ISO 9000, Sardar Patel University. Vallabh Vidyanagar.

[4] Joseph,A.GliemandRosemary .Glien(2003)Calculating, Interpreting, and Reporting Cronbach'sAlpha Reliability Coefficient for Likert-Type Scales,Midwest Research ro Practice Conference in Adult Continuing and Community.

[5] Jan Stringer,Dr., "factors that affect Employee's productivity" ,http://www.nbrii.com/employee-survey white papers,pp.1-2,2013.

[6] Malhotra Naresh K.,(2009). Marketing Research- an Applied Orientation, fifth edition, Pearson, New Delhi.

[7] Nargundkar Rajendra (2005). Marketing ResearchText and Cases, Tata McGraw-Hill Pub., New Delhi.

[8] Pandya,K. J. (2010). Ph.D.Thesis, Consumer Behaviour in Two Wheeler Industry: A case study of Motorcycle users in the state of Gujarat, Sardar Patel University, Vallabh Vidyanagar.

[9] Pankhania, T. B., Modi,V. K., (2011), The Factors influencing Target Market criteria: A survey conducted inindustries at Vitthal Udyognagar in Anand District ofGujarat State, India,International Journal of IndustrialEngineering \& Production Research,September2011,Volume22,Number3, pp.213220.

[10] Pankhania,T.B., (2011), Ph.D. Thesis, Industrial productivity scenario and potentiality in Vitthal Udyognagar in Anand district of Gujarat, India, Sardar Patel University, Vallabh Vidyanagar, Gujarat.

[11] Pankhania,T.B.\& Modi V.K. (2013), Impact of various aspects on Industrial Performance enhancing Productivity. International Journal of Engineering and InnovativeTechnology,Feb.2013,Vol.2,Issue-8,166171.

[12] Rahman A.,Kalam A., Rahman,M., "The Influence of service Qouality and Price ON Customer Satsfaction: An Empirical Study on Restaurant Services In Khulna

[13] Division", IndustrialEngineering Letters, Vol.2,No.2, 2012, pp.25-32.

[14] Rinalini Pathak Kakati and U R Dhar(2002), Competitive Strategies and New Venture Performance, Vikalpa,The Journal for Decision Makers, IIM of Management, Ahmadabad, India, 27(2),19-34.

[15] Seth, Anita, Momaya K, Gupta (2008). Managing the Customer Perceived Service Quality for Cellular MobileTelephony: An Empirical Investigation, Vikalpa,
The Journal for Decision Makers, Indian Institute of Management, Ahmadabad, India, 33(1), 19-34.

[16] Sharma, K. V. S., (2006). Statistics Made Simple. Do it yourself on PC". Prentice-Hall of India, New Delhi.

[17] Russell Roberta S. and Taylor Bernard W.,"Operations Management" along the supply chain, Wiley India, New Delhi,2011,pp.9-12.

[18] Akshay, A.Pujara, Virendra, K.Parmar and Dr. Ravikant,"Industrial Safety and Maintenance Engineering" Books India Publications, Ahmadabad, 2013, pp.10-11.

[19] Charles A. Gaulin, Jr.,"Industrial Accident Prevention" Intonations Correspondence Schools Division of Intext, USA, 1968, pp.19-20.

\section{BIOGRAPHIES}

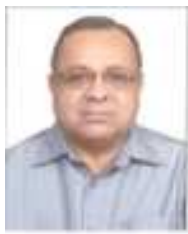

Dr.T.B.Pankhania, Associate Professor in Mechanical Engineering and Head, Workshop at B.V.M. Engineering College, Sardar Patel University, Vallabh Vidyanagar. He obtained his B.E. (Mech), M.E. (Mech), and Ph.D. from Sardar Patel University (SPU); Vallabh Vidhyanagar. His profile includes a stint of over 37 years of experience. He has published his 19 research papers in national and international journals and presented 6 research papers in International conferences.

Email: tbp@sify.com

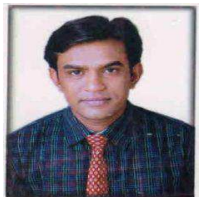

Akil H. Jariya, Assistant Professor in Production Engineering at B.V.M. Engineering College, Gujarat Technological University, Ahmadabad; He obtained his B.E. (Mech.) from Bhavnagar University, Gujarat and M. Tech. (Mech.) from Nirma University, Ahmadabad, Gujarat. He has 4 years of teaching experience $\mathrm{He}$ has published his 2 research papers in international journals. His current areas of interest are CAD/CAM, Industrial Engineering and Managing Project.

E-mail: jariya_akil@yahoo.com

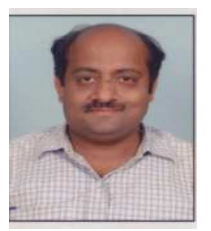

V.K.Modi, Lecturer in Mechanical Engineering at B \& B Institute of Technology, Vallabh Vidyanagr.He obtained his master degree from M.S.University, Baroda. His areas of the interest are CAD-CAM and Industrial Engineering. He has 21 years of teaching experience. He has published seven research papers in National and International Journals and presented eight research papers in international conferences.

E-mail: modi_vinit@yahoo.com 


\section{Appendix: Questionnaire}

\section{[A] Category of the company:}

Small Scale

Medium Scale

Large Scale

\section{[B] Globalization and Competitiveness:}

Do you agree that productivity has increased due to globalization and competitiveness?

\begin{tabular}{|c|c|c|c|c|c|c|}
\hline $\begin{array}{l}\text { Sr. } \\
\text { No }\end{array}$ & Statements & $\begin{array}{l}\text { Strongly } \\
\text { agree (05) }\end{array}$ & $\begin{array}{c}\text { Agree } \\
(04)\end{array}$ & $\begin{array}{l}\text { Neutral } \\
(03)\end{array}$ & $\begin{array}{l}\text { Disagree } \\
(02)\end{array}$ & $\begin{array}{c}\text { Strongly } \\
\text { disagree }(01) \\
\end{array}$ \\
\hline 1. & $\begin{array}{l}\text { Globalization has changed the industrial } \\
\text { scenario. }\end{array}$ & & & & & \\
\hline 2. & $\begin{array}{l}\text { Globalization has increased Job opportunities, } \\
\text { productivity and living standard. }\end{array}$ & & & & & \\
\hline 3. & $\begin{array}{l}\text { Liberalization has improved } \\
\text { performance and competitiveness. }\end{array}$ & & & & & \\
\hline & $\begin{array}{l}\text { Privatization is very essential to improve } \\
\text { industrial performance in the highly } \\
\text { competitive world }\end{array}$ & & & & & \\
\hline 5. & $\begin{array}{l}\text { ISO certification helps improve the image of } \\
\text { the company }\end{array}$ & & & & & \\
\hline 6. & $\begin{array}{l}\text { ISO certification helps increase exports, } \\
\text { profit, turnover, expectations of the company }\end{array}$ & & & & & \\
\hline 7. & ISO certification helps increase, productivity. & & & & & \\
\hline
\end{tabular}

